\title{
THE EFFECT OF THE DRUG «COBAZIN» ON THE PRODUCTIVE INDICATORS OF BEE COLONIES
}

\author{
Dmytro Kisil \\ Department of Veterinary Examination, Microbiology, \\ Zoohygiene and Safety and Quality of Livestock Products ${ }^{l}$ \\ Dima_kisill@meta.ua \\ Tetiana Fotina \\ Department of Veterinary Examination, Microbiology, \\ Zoohygiene and Safety and Quality of Livestock Products ${ }^{I}$ \\ oshkromada@gmail.com \\ Svitlana Nazarenko \\ Department of Veterinary Examination, Microbiology, \\ Zoohygiene and Safety and Quality of Livestock Products ${ }^{I}$ \\ nazarenko.sveta2014@gmail.com \\ ${ }^{1}$ Sumy National Agrarian University \\ 160 Herasyma Kondratieva str., Sumy, Ukraine, 40021
}

\begin{abstract}
The aim of the study was to determine the effectiveness of the drug «Cobazin» on the productivity of bee colonies during the increase in strength (increase in the number of young bees in the bee colony) in spring and autumn.

Materials and methods. Control and experimental groups were formed to test «Cobazin» feed supplement. It was fed 5 times with an interval of 5 days. Bee colonies from the control group received a pure sugar solution (1:1) in the amount of 0.5 liters per bee colony, and the experimental group received a sugar solution of 0.5 liters per bee colony (1:1) with the addition of the drug «Cobazin» in the amount of $2.5 \mathrm{~g}$.

Indicators characterizing the development of bee colonies were determined by a measuring frame of $5 \times 5 \mathrm{~cm}$ in size, for 12 days to cover the total number of eggs laid by the queen bee during feeding. Four measurements were performed during the study. The results of the control and experimental groups were compared and the significance of the differences between them was established. There was a comparison of the difference between groups of bees both fed pure sugar syrup in a ratio of 1:1 and syrup with the addition of the drug «Cobazin».

Results. It is proved that during the feeding period the number of brood in bee colonies that received feed supplement «Cobazin» increased significantly by $76 \%$ (71 \% in the group that received only sugar solution without this drug). Live weight of queen bees in colonies that were stimulated with «Cobazin» was actually $2 \%$ higher compared to the control group.

It was found that at the end of the bee season, bee colonies fed in May with the feed supplement «Cobazin» had significantly higher values of strength, number of sealed brood and live queen bees compared to those who received pure sugar solution. The brood in the control group was $25 \%$ lower than in the experimental group.

Conclusions. For the first time it was proved that the use of feed supplement «Cobazin» in combination with sugar solution has a positive effect on the features that characterize the development of bee colonies (strength, number of sealed brood) and their health productivity. The positive impact is observed not only during feeding, but also in subsequent periods of colony development.

Keywords: Cobazin, bee colony, stimulants, colony strength, bee, productivity, health productivity, cobalt, germanium, zinc, immunostimulant, honey, queen bee, brood.
\end{abstract}

DOI: $10.21303 / 2504-5679.2021 .001711$

\section{Introduction}

The object of the study is the developed immunomodulatory feed supplement «Cobazin» (Brovapharma Ltd.) on the basis of three active components: cobalt $-0.4 \mathrm{mg}$; zinc $-0.8 \mathrm{mg}$; germanium $-0.08 \mathrm{mg}$.

Beekeeping in modern market conditions is impossible without high profitability of apiaries. High profitability is created by a set of conditions. Not the least of them is the health of bees 
Healthy bees are one of the conditions for good wintering, rapid spring development and high honey yields. One of the main tasks in the beekeeping industry is to increase the number of bee colonies and their productivity [1, 2]. Given these goals, not the last place in the stage of breeding honey bees is stimulating the reproduction of bee colonies during their development. It has already been proven that natural food for bees (nectar, honey, pollen, and royal jelly) provide a sufficient amount of minerals and vitamins. Despite this, very often in certain periods of bee colonies development they are fed with feed, which contains stimulants [3, 4].

In beekeeping practice, a number of mineral salts and vitamins with a proven positive effect on increasing the productive performance of bees, increasing the strength of bee colonies (increasing the number of bees in the bee colony) are used as stimulants for feeding bees to increase the strength of the bee colony. That means the increase in egg-laying of the queen bee to a certain maximum (depending on the breed of bees), and resistance of bees to infectious diseases of bee colonies $[5,6]$.

The literature does not describe the experience of scientists using combined drugs based on the chemical elements cobalt, germanium and zinc, which stimulate the bee colony in spring and autumn to increase the birth rate of young bees in the cells of the brood cell comb [7, 8]. In early spring, when the bee colony's primary goal is to increase the strength of the bee colony, for example, to increase the number of bees in the hive before the main honey harvest during the flowering period in sunflower fields in the North-Eastern region of Ukraine. Following a logical chain, more bees in a bee colony - more honey is produced by the bee colony by increasing the number of worker insects in the hive that are able to collect a nectar from honey plants $[9,10]$. But, at the same time, if the bee colony is not able to increase the corresponding force (up to 9 inter frame spaces in 10 frame hive) - it automatically becomes unprofitable and less resistant to infectious and parasitic diseases. Although there are data on beekeepers that used cobalt or vitamin B12 during the feeding of bee colonies, there is a need to offer a combined stimulant for use in the practice of beekeepers [11, 12].

The aim of the research was to conduct experimental studies to determine the effectiveness of the use of a new immunomodulatory feed supplement «Cobazin», based on cobalt, germanium and zinc in the period of bee colonies feeding to increase the strength of bee colonies.

\section{Materials and methods}

Bee colonies were housed in 10-frame hives, according to the standards of the American scientist of French origin - «Charles Dadan». They were $435 \times 300 \mathrm{~mm}$ in size and equipped with longitudinal ventilation of frames with honeycombs. The feeding was carried out 5 times with an interval of 5 days. Control and experimental groups of 10 bee colonies were formed to test the feed supplement «Cobazin» starting from 01.05.2018. Bee colonies from the control group received a pure sugar solution (in a ratio of water and sugar 1:1) in the amount of 0.5 liters per bee colony. The experimental group received a sugar solution of 0.5 liters per bee colony (in a ratio of water and sugar 1:1) with the addition of the drug «Cobazin» in the amount of $2.5 \mathrm{~g}$ for every 0.5 liters. Indicators characterizing the development of bee colonies were determined by a frame for measurements (size of squares was $5 \times 5 \mathrm{~cm}$ ) for 12 days to cover the total number of eggs laid by the queen bee during feeding. During the experiment, four measurements were performed on May 01, May 13, May 25 and June 06, 2018, respectively. During the measurements, changes in the following indicators were observed:

- strength of bee colonies, expressed by the number of bee colonies, in the inter frame distances densely covered with bees and accordingly calculated in kilograms;

- the amount of honey in the beehive - in $\mathrm{kg}$;

- the amount of pollen in beehives - in $\mathrm{cm}^{2}$;

- the number of sealed brood of worker bees - the number of hives.

The amount of honey obtained from the bee colony $(\mathrm{kg})$ during the main collection was determined using a measuring frame. After the last pumping of honey at the end of the bee season (August 30, 2018), the main autumn inspection and preparation of colonies for winter was carried out. The above parameters were measured using a measuring frame. The main inspection of bee colonies before wintering was carried out on October 9, 2018 and indicators that characterized the development of colonies were measured. The obtained results were statistically processed 
using Microsoft Office Excel software, according to the Fisher - Student test, taking into account the arithmetic means and their statistical errors, as well as determining the probable difference between the indicators that were leveled. The arithmetic mean $(M)$ and the standard error of the arithmetic mean $(m)$ were determined for each experimental indicator. Probable differences were considered with a significance level of more than $96 \%(p<0.05)$.

The results of the control and experimental groups were compared and the significance of the differences between them was established. There was a comparison of the difference between groups of bees both fed pure sugar syrup in a ratio of 1:1 and syrup with the addition of the drug «Cobazin». As the sugar syrup itself is already a kind of stimulant for the bee colony, that is, in the presence of a sugar solution in the bee colony, the queen bee understands that the hive has food reserves for future newborn young worker bees. Therefore, the effectiveness of the immunostimulant - «Cobazin» and its advantages over feeding pure sugar syrup was determined.

\section{Results}

The results of the bee colonies development in the first period of feeding are presented in Table 1. The data indicate that at the beginning of the experiment (May 1) the differences in the average values of the measured indicators are significant. It means that at the beginning the bee colonies from control and experimental groups are equal. Regarding the strength of colonies, there was a gradual increase in both groups. The observed differences in the average values of colony strength before feeding and after the last feeding are highly significant.

\section{Table 1}

Data on the development of bee colonies during the feeding period with the addition of feed supplement «Cobazin» are reflected in the form of arithmetic mean values $(M)$ and their standard error of the arithmetic mean value $(m)$ according to the method $(M \pm m)$

\begin{tabular}{cccccc}
\hline Reporting periods & Groups & $\begin{array}{c}\text { Strength } \\
\mathbf{( k g )}\end{array}$ & Pollen $\left.\mathbf{( c m}^{\mathbf{2}}\right)$ & $\begin{array}{c}\text { Brood (number of } \\
\text { honeycombs) }\end{array}$ & $\begin{array}{c}\text { Live weight of queen } \\
\text { bees }(\mathbf{m g})\end{array}$ \\
\hline \multirow{2}{*}{ May 1 } & $\begin{array}{c}\text { control } \\
\text { experiment }\end{array}$ & $1.1 \pm 0.1$ & $102.5 \pm 22.5$ & $3570 \pm 301$ & $268.8 \pm 7.5$ \\
& $1.1 \pm 0.1$ & $102.8 \pm 14.5$ & $3600 \pm 203$ & $273.2 \pm 4.7$ \\
May 13 & control & $1.4 \pm 0.1$ & $126.7 \pm 25.7$ & $6080 \pm 614$ & $269.6 \pm 7.6$ \\
& experiment & $1.5 \pm 0.1$ & $127.5 \pm 25.9$ & $6790 \pm 685$ & $276.2 \pm 4.9$ \\
May 25 & control & $1.7 \pm 0.1$ & $219.0 \pm 42.1$ & $10020 \pm 651$ & $271.4 \pm 7.6$ \\
& experiment & $1.8 \pm 0.1$ & $227.5 \pm 63.6$ & $12040 \pm 565$ & $281.8 \pm 5.5$ \\
June 6 & control & $1.9 \pm 0.1$ & $247.5 \pm 58.8$ & $12400 \pm 834$ & $271.6 \pm 7.3$ \\
& experiment & $2.0 \pm 0.1$ & $327.5 \pm 97.5$ & $15210 \pm 652$ & $283.6 \pm 4.7$ \\
Significance of the dif- & control & $p \leq 0.1$ & & $p \leq 0.1$ & $p \leq 0.1$ \\
ference beginning/end & experiment & $p \leq 0.1$ & & $p \leq 0.1$ & $p \leq 0.1$
\end{tabular}

Analysis of the data from the last measurements after the end of feeding (June 6) showed a one-sided and similar in the influence degree of feeding both the group to which the pure sugar solution was given and the group to which the «Cobazin» supplement was given. A clear positive effect of feeding with the «Cobazin» supplement was observed in the number of generations raised in bee colonies. There was also a small difference in pollen measurements $\left(\mathrm{cm}^{2}\right)$ and no significant advance in the strength of bee colonies. That is, there was a significant difference. There was a tendency to gradually increase the sealed brood and this was followed by an increase in the strength of bee colonies in beehives, and the increase was in the experimental group.

Analysis of the results represented in Table 1 show that feeding bee colonies with a solution of sugar and «Cobazin» supplement has a positive effect on the characteristics of bee colonies such as strength, number of broods fed, and live weight of queens. This is evidenced by the differences in the indicators in the range from medium to high values of the traits that were observed during the experiments in the control and research groups. Table 2 shows the measurement data in bee colonies in preparation for wintering (August 30) and during wintering (October 9). The results show 
that at the end of the bee season (it was the end of August for the experimental area), bee colonies from the experimental group (fed during May with the addition of «Cobazin» feed supplement) had higher reliable indicators of strength, number of sealed brood and live weight of queen bees in comparison with the control group (fed only with sugar solution). Calculations based on the database show that the brood in the control group was more than $58 \%$ lower, and the live weight of queen bees was almost $10 \%$ lower compared to the experimental group. in Table 2.

The condition of bee colonies in preparation for wintering and actual wintering is presented

Analysis of the results for winter preparation shows that the effect of the stimulant «Cobazin» persists and bee colonies that were fed this feed supplement at the beginning of the season, enter the inactive period of their lives with more bees. Most of the sealed brood in these colonies (calculated during winter preparation on August 30) showed that in bee colonies bees were young or similar to them by their physiological condition and productivity. There were more bees (young, able to perform field work and resistant to insecticides) in beehives prepared for wintering that, respectively, guaranteed better wintering. The increase of the queen bee reproductive function, characterized by the laying of more eggs in the cells of the brood frame, resulted in an increase in the number of young worker bee exits from the cells of the brood cells comb. Following the logical chain, from the increase of worker bees amount, which provide flower nectar to the honeycomb cells, accordingly, the stocks of honey and pollen in the hive (bee colony), which is the biological food of bees and is stored in «feed» hives in winter, increase. The standard norms are $2.5 \mathrm{~kg}$ per one bee honeycomb frame. The data are presented in Table 2. At this stage of preparation for winter, the beekeeper is faced with a choice:

1) pump out all the total honey so that it is marketable for consumption, leaving no honey. Give only completely sugar syrup in a ratio of 1:1 in winter;

2) leave honey for wintering at the rate of $2.5 \mathrm{~kg}$ per bee frame.

The experiment followed variant «2» - to leave the honey to the bee colony in winter in accordance with the norms $-2.5 \mathrm{~kg}$ per bee colony because the honey contains more natural sugars - fructose and glucose.

Table 2

Data on the state of bee colonies in preparation for wintering and wintering itself, are reflected in the form of arithmetic mean values $(M)$ and their standard error of arithmetic mean value $(m)$ according to the method $(M \pm m)$

\begin{tabular}{|c|c|c|c|c|c|c|}
\hline $\begin{array}{l}\text { Reporting } \\
\text { periods }\end{array}$ & Groups & Strength (kg) & Honey (kg) & Pollen $\left(\mathrm{cm}^{2}\right)$ & $\begin{array}{l}\text { Brood (number of } \\
\text { honeycombs) }\end{array}$ & $\begin{array}{l}\text { Weight of bee } \\
\text { queens (mg) }\end{array}$ \\
\hline \multirow{3}{*}{$\begin{array}{c}\text { Preparing } \\
\text { for winter } \\
\text { (August 30) }\end{array}$} & control & $2.1 \pm 0.1$ & $10.6 \pm 0.7$ & $14.5 \pm 20.6$ & $5890 \pm 557$ & $232.8 \pm 7.5$ \\
\hline & experimental & $2.2 \pm 0.1$ & $11.1 \pm 0.8$ & $157.5 \pm 26.1$ & $7810 \pm 404$ & $257.8 \pm 4.1$ \\
\hline & $\begin{array}{c}\text { control } \\
\text { experimental }\end{array}$ & $p \leq 0.05$ & & & $p \leq 0.01$ & $p \leq 0.01$ \\
\hline \multirow{3}{*}{$\begin{array}{l}\text { Wintering } \\
\text { (October 9) }\end{array}$} & control & $1.6 \pm 0.1$ & $9.6 \pm 0.4$ & $10.0 \pm 5.5$ & $50 \pm 34$ & \\
\hline & experimental & $1.9 \pm 0.1$ & $9.7 \pm 0.5$ & $12.5 \pm 4.2$ & $90 \pm 23$ & - \\
\hline & $\begin{array}{c}\text { control } \\
\text { experimental }\end{array}$ & $p \leq 0.01$ & - & - & - & - \\
\hline
\end{tabular}

Therefore, Table 2 presents the condition of bee colonies, the amount of pure honey and pollen left in the bee colony during the preparation of the bee hive for winter, that is, inspection of the presence of bee food in winter - honey and pollen, in accordance with the rules $(2.5 \mathrm{~kg} / \mathrm{bee}$ colony) taking into account the approximation, without impurities of sugar syrup.

Thus, the use of «Cobazin» feed supplement in bee colonies in spring retains its positive effect on the indicators that characterize the state of the bee colony at the end of the bee season. The amount of commercial honey obtained (as a final product) for human consumption, from bee colonies that were included in the experiment, is shown in Table 3. 
Table 3

Data on the amount of marketable honey $(\mathrm{kg})$ obtained from one bee colony are displayed as arithmetic mean values $(M)$ and their standard error of arithmetic mean value $(m)$ according to the method $(M \pm m)$

\begin{tabular}{ccc}
\hline Groups & The total amount of honey & Including centrifuged \\
\hline Control group & $23.71 \pm 2.59$ & $12.22 \pm 2.17$ \\
Experimental group & $30.25 \pm 1.34$ & $19.35 \pm 1.78$ \\
Probability & $p \leq 0.05$ & $p \leq 0.01$
\end{tabular}

The data show that in the experimental group more honey was obtained, both total and marketable, compared to the control group. This result was the same even after the process of centrifugation of honey using imported special equipment - automatic «honey extractor Lyson Classic» $(\varnothing 1200$, the speed of turnover equaled $3000 / \mathrm{min}$ ), which allowed to remove the final high-quality commercial honey from the cells of the honeycomb, the moisture content of which was $18-20 \%$.

\section{Discussion of research results}

It is proved that the use of «Cobazin» feed supplement at a dose of $2.5 \mathrm{~g} / 500 \mathrm{ml}$ of sugar solution 5 times with an interval of 5 days has a positive effect on the characteristics of bee colonies (strength, number of sealed brood) and their health. The positive impact is observed not only during feeding, but also in subsequent periods of colony development.

It was found that at the end of the bee season, bee colonies fed in May with «Cobazin» feed supplement have significantly higher values of strength, number of sealed brood and live queen bees compared to those who received pure sugar solution. The amount of brood in the control group was lower by $25 \%$ compared with the experimental group [13, 14].

Bee colonies that received «Cobazin» feed supplement during winter preparation had more bees than those fed with only sugar solution. The total amount of honey obtained from colonies fed at the beginning of the bee season with «Cobazin» feed supplement was $37 \%$ more compared to the control group $[15,16]$.

Compared with previous studies by other scientists, it was found that the use of feed supplements «Glutam 2BM» and «Nanostimulin», the active ingredient of which is a mixture of monosodium glutamate and cobalt aquachelate, and feeding bee colonies with sugar syrup with biologically active substances contributed to the intencification of egg production. The highest egg production, compared to the control $(698.3 \pm 228.05)$, had those queen bees, whose colonies were fed with supplements «Glutam 2BM» (1188.0 \pm 265.86$)$ and «Nanostimulin» $(1305.8 \pm 407.05)[17,18]$. At the same time, queen bees show significant individual features of egg production during colonies feeding of pure sugar syrup and with the addition of biologically active substances. Insufficient amount of pollen in the bee colony probably reduces the effectiveness of the stimulating effect on the egg production of the queen bee by feeding them with sugar syrup and with the addition of biologically active substances $[19,20]$.

Study limitations. The research limitation is the use of a small number of bee colonies, both experimental and control groups as well as an insufficient study of the differentiation of bee breeds from other regions, their breeding line and generation on the effectiveness of the «Cobazin» feed supplement.

Prospects for further research. The study is based on the use of more bee colonies, both experimental and control groups, and greater differentiation of bee breeds, including other regions of Ukraine and abroad, on the effectiveness of the «Cobazin» feed supplement.

\section{Conclusions}

The obtained results show that the immunomodulatory feed supplement «Cobazin» is effective in building up bee colonies both before the main honey harvest and before winter. The efficiency is observed on the increased number of young bees grown in bee colonies. Brood in the experimental group was registered correspondingly higher in comparison with the control group. 
More honey was picked from bee colonies of the experimental group, respectively, than in the control group. A similar trend is observed when studying the amount of pollen obtained from the experimental group in comparison with the control.

The practical value of the experiments is to study the effectiveness of «Cobazin» feed supplement in feeding bee colonies while increasing the strength of bee colonies and obtaining more honey and pollen from one bee colony.

\section{Conflicts of interest}

The authors declare that they have no conflicts of interest.

\section{Acknowledgements}

The materials presented in the article are a fragment of scientific research of the Department of Veterinary and Sanitary Expertise, Microbiology, Zoohygiene and Safety and Quality of Livestock Products of Sumy National Agrarian University according to the thematic plan of research work of the University «Implementation of better methods of diagnosis, treatment and prevention of infectious animal diseases» No. of State registration 0198U001290 (Reg. No. 41/1).

\section{References}

[1] Musiyenko, O. V., Kysterna, O. S. (2017). Putrefactive diseases of bees, features of diagnosis and control. Bulletin of Sumy National Agrarian University. Series: Veterinary Medicine, 11 (1), 90-95.

[2] Kisil, D. O., Fotina, T. I. (2018). Monitoring the epizoetic situation on mixed infectious diseases in bees in Northern Eastern region of Ukraine. Scientific Messenger of LNU of Veterinary Medicine and Biotechnologies, 20 (83), 381-384. doi: http:// doi.org/10.15421/nvlvet 8375

[3] Neumann, P., Elzen, P. J. (2004). The biology of the small hive beetle (Aethina tumida, Coleoptera: Nitidulidae): Gaps in our knowledge of an invasive species. Apidologie, 35 (3), 229-247. doi: http://doi.org/10.1051/apido:2004010

[4] Berezovsky, A. (2012). Nosematosis is a problematic disease of bee colonies. Ukrainian beekeeper, 9, $22-24$.

[5] Ao, Y., Chen, J., Yue, J., Peng, R.-X. (2008). Effects of 18a-glycyrrhizin on the pharmacodynamics and pharmacokinetics of glibenclamide in alloxan-induced diabetic rats. European Journal of Pharmacology, 587 (1-3), 330-335. doi: http:// doi.org/10.1016/j.ejphar.2008.03.043

[6] Puente, J., Gascon, F., Ponte, B., de la Fuente, D. (2019). On strategic choices faced by large pharmaceutical laboratories and their effect on innovation risk under fuzzy conditions. Artificial Intelligence in Medicine, 100, 101703. doi: http:// doi.org/10.1016/j.artmed.2019.101703

[7] Lim, W., Chia, Y., Liong, S., Ton, S., Kadir, K., Syed Husain, S. (2009). Lipoprotein lipase expression, serum lipid and tissue lipid deposition in orally-administered glycyrrhizic acid-treated rats. Lipids in Health and Disease, 8 (1), 31. doi: http:// doi.org/10.1186/1476-511x-8-31

[8] Fox, N. J., Ward, K. J. (2008). Pharma in the bedroom ... and the kitchen ... The pharmaceuticalisation of daily life. Sociology of Health \& Illness, 30 (6), 856-868. doi: http://doi.org/10.1111/j.1467-9566.2008.01114.x

[9] Koga, K., Kawashima, S., Shibata, N., Takada, K. (2007). Novel Formulations of a Liver Protection Drug Glycyrrhizin. Yakugaku Zasshi, 127 (7), 1103-1114. doi: http://doi.org/10.1248/yakushi.127.1103

[10] Hanje, A. J., Fortune, B., Song, M., Hill, D., McClain, C. (2006). The Use of Selected Nutrition Supplements and Complementary and Alternative Medicine in Liver Disease. Nutrition in Clinical Practice, 21 (3), 255-272. doi: http://doi.org/10.1177/ 0115426506021003255

[11] Lu, L. G., Xu, H. J., Wang, Y. J. (2005). Therapeutic effect of diammonium glycyrrhizinate lipid ligand on carbon-tetrarchloride induced fatty livers in rats. Zhonghua Gan Zang Bing Za Zhi, 10, 786-788.

[12] Tripathi, M., Singh, B. K., Kakkar, P. (2009). Glycyrrhizic acid modulates t-BHP induced apoptosis in primary rat hepatocytes. Food and Chemical Toxicology, 47 (2), 339-347. doi: http://doi.org/10.1016/j.fct.2008.11.028

[13] Kisil, D. O. (2019). Determination of veterinary - sanitary assessment of honey and its level of toxicity after the application of food additive «Ковасіn» for stimulation the power of beees families and comparative safety assessment with other analoges. Scientific and Technical Bulletin of the Institute of Veterinary Drugs and Feed Additives Institute of Animal Biology, 20 (2), 311-316. doi: http://doi.org/10.36359/scivp.2019-20-2.40

[14] Sirenko, O. S., Desyatnikova, O. V., Gurieva, V. B. (2019). Effectiveness of the "Guanidez" disinfectant on the agents of bee infectious diseases in laboratory conditions. Veterinary Medicine: Inter-Departmental Subject Scientific Collection, 105 (1), 59-62. doi: http://doi.org/10.36016/vm-2019-105-11 
[15] Kysterna, O. S., Harkava, V. V., Musiienko, O. V. (2014). Features of preparation of smears of hemolymph of an imago bee. The Animal Biology, 16 (4), 118.

[16] Danihlík, J., Aronstein, K., Petřivalský, M. (2015). Antimicrobial peptides: a key component of honey bee innate immunity. Journal of Apicultural Research, 54 (2), 123-136. doi: http://doi.org/10.1080/00218839.2015.1109919

[17] Gatschenberger, H., Gimple, O., Tautz, J., Beier, H. (2012). Honey bee drones maintain humoral immune competence throughout all life stages in the absence of vitellogenin production. Journal of Experimental Biology, 215 (8), 1313-1322. doi: http:// doi.org/10.1242/jeb.065276

[18] Vedmed, I. V., Sheremeta, V. I., Kaplunenko, V. G. (2018). Melliferous capacity of bee families depending on the quality of queen bees, derived with using of biologically active feeding. Animal Breeding and Genetics, 51, 296-302. doi: http://doi.org/ 10.31073/abg.51.40

[19] El Mohandes, S., Nafea, E., Fawzy, A. (2010). Effect of different feeding diets on the haemolymph of the newly emerged honeybee workers Apis mellifera L. Egyptian Academic Journal of Biological Sciences. A, Entomology, 3 (1), $113-220$. doi: http://doi.org/10.21608/eajbsa.2010.15257

[20] Richardson, R. T., Ballinger, M. N., Qian, F., Christman, J. W., Johnson, R. M. (2018). Morphological and functional characterization of honey bee, Apis mellifera, hemocyte cell communities. Apidologie, 49 (3), 397-410. doi: http://doi.org/10.1007/ s13592-018-0566-2

How to cite: Kisil, D., Fotina, T., Nazarenko, S. (2021). The effect of the drug «Cobazin» on the productive indicators of bee colonies. EUREKA: Health Sciences, 2, 90-96. doi: http://doi.org/10.21303/2504-5679.2021.001711 